\title{
Optimization of an Online Post-Column Derivatization System for Ultra High-Performance Liquid Chromatography (UHPLC) and Its Applications to Analysis of Biogenic Amines
}

\author{
Satoe IIJIMa, *† Yasuyo SAto,* Masao Bounoshita, ${ }^{*}$ Toshihiko MiYaJI, ${ }^{*}$ David J. Tognarelli,** \\ and Muneo SAITO*
}

*LC and SFC Applications Laboratory, JASCO Corporation, 2967-5, Ishikawamachi, Hachioji, Tokyo 192-8537, Japan

** JASCO Incorporated, 28600 Mary's Court, Easton, MD 21601, USA

\begin{abstract}
We investigated the efficacy and utility of a post-column derivatization method for the detection of amines with $o$-phthalaldehyde (OPA) in ultra high-performance liquid chromatography (UHPLC). Since it was anticipated that a derivatization reaction system placed downstream of the column would give considerable band broadening to narrow peaks generated by a UHPLC column, we examined the contributions of the dimensions of the reaction tube, the fluorescence (FL) detector flow cell, and the column to the extra-column peak broadening, and optimized the post-column derivatization system in UHPLC. We successfully separated amines within 6 min with gradient elution by using the post-column derivatization system connected to a UHPLC system. The analysis time was reduced by a factor of 7 compared with that by conventional HPLC. The detection limits were $18.0-105.7 \mathrm{fmol}$, depending on the compounds; the reproducibilities were $0.11-0.82 \%$ RSD for the retention times and $0.78-1.66 \%$ RSD for the peak areas $(n=10)$, respectively. The linear dynamic ranges were up to 12,20 , and $40 \mathrm{pmol} / \mu \mathrm{L}$, depending on the compounds, respectively.
\end{abstract}

(Received February 25, 2013; Accepted April 1, 2013; Published May 10, 2013)

\section{Introduction}

Derivatization detection methods have been extensively used in HPLC to detect compounds that cannot be detected by existing detectors, or to enhance the sensitivity and selectivity in detection. Such detection methods can be categorized into two: one based on pre-column derivatization, and the other on postcolumn derivatization. In the former method, the derivatization reaction takes place before analytes are injected onto the column, while in the latter method the derivatization reaction occurs to analytes after separation by the column. ${ }^{1}$

Generally, the latter method minimizes the sample manipulation, and it is suitable for an automated analysis. However, few reports on online post-column derivatization have been found concerning ultra high-performance liquid chromatography (UHPLC), because it is generally believed that the high resolution achieved by a UHPLC column is deteriorated as well as the detection limits due to additional dispersion of the analyte peaks inside the derivatization system. ${ }^{2}$

The aim of this study was to develop a high-performance post-column $o$-phthalaldehyde (OPA) derivatization system that can readily be used in connection with UHPLC. We examined the contributions of the reaction tube dimensions, the volume of the detector's flow cell, and the column dimensions to the extra-

To whom correspondence should be addressed.

E-mail: satoe.iijima@jasco.co.jp

This article was presented in part as poster No. P-475-Wed at HPLC 2012, June 16 - 21 held in Anaheim, CA, USA. column peak broadening, and optimized the post-column derivatization system with OPA..$^{3-7}$

There has been a growing demand for high-speed, highly efficient and sensitive analysis for biogenic amines in food from the viewpoint of food safety. Histamine has been considered to be a cause of food poisoning, and is regarded as an indicator of rotten seafood and meats. In the U.S., there is seafood HACCP (Hazard Analysis Critical Control Point) regulated by the FDA (Food and Drug Administration). The seafood HACCP is a systematic preventive approach to seafood safety practiced in the food industry. It also mentions food poisoning caused by histamine. In addition to histamine, cadaverine, spermidine, tyramine, and putrescine have also been regarded as being indicators of spoiled seafood and meats; HPLC is listed as the standard measurement method for the analysis of these amines by the Ministry of Health, Labour and Welfare in Japan.

Polyamines are synthesized in the cells of all living organisms, and are related to the growth and differentiation of cells. Recently, it was reported that polyamines, such as spermidine and spermine, play an important role in the inhibition of Leukocyte Function Antigen-1 (LFA-1) related to the induction of inflammation, immune function, and the arteriosclerosis process. ${ }^{8,9}$ Since polyamines orally taken are directly absorbed, more attention has been given to food rich in polyamines for the possibility of controlling arteriosclerosis.

Both pre-column and post-column derivatization methods for amine analyses have been extensively used in HPLC to improve the sensitivity and selectivity. ${ }^{10-17}$ A post-column derivatization method is the much preferred method for amines, because it offers easy operation, less sample manipulation, and high 


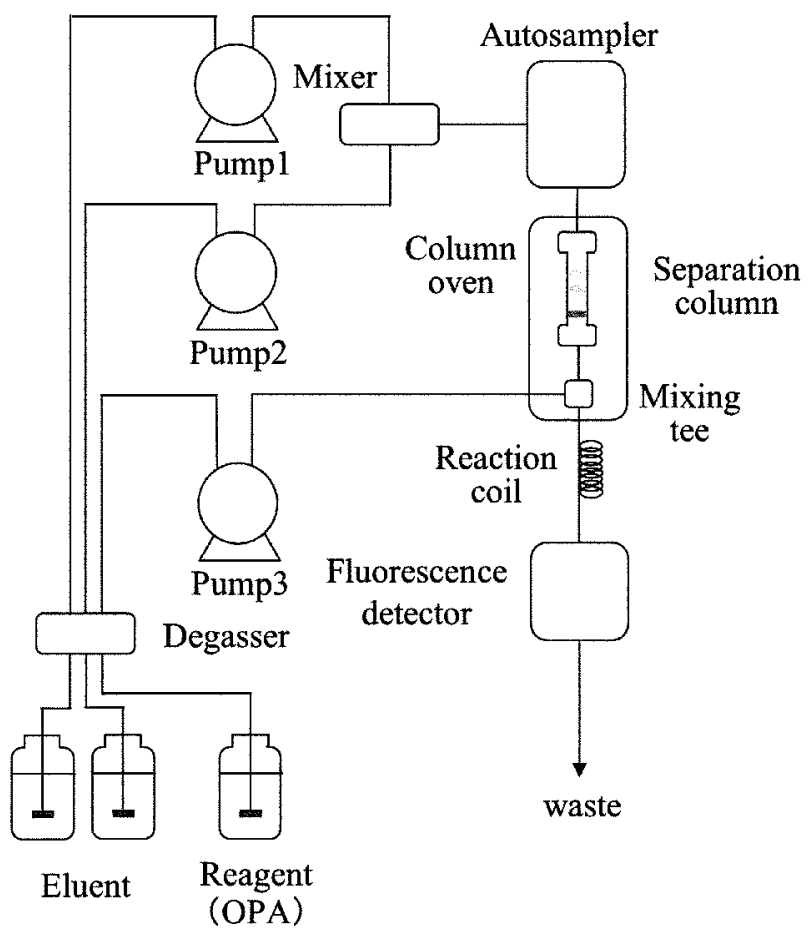

Fig. 1 Schematic diagram of the UHPLC system with an FL detector for post-column derivatization.

sensitivity and selectivity. ${ }^{18}$

In this paper, we present a high-speed separation method of amines including several polyamines using the newly developed post-column derivatization system connected to UHPLC and its applications to food analysis.

\section{Experimental}

\section{Apparatus}

Figure 1 shows a schematic diagram of the system we developed, which consists of 3 JASCO X-LC 3185PU pumps, an X-LC 3080DG degasser, an X-LC 3180MX gradient mixer, an X-LC 3159AS auto-sampler, and an X-LC $3167 C O$ column oven. An X-LC 3185PU pump for the derivatization reagent was equipped with a tube $(0.064 \mathrm{~mm}$ i.d. $\times 500 \mathrm{~mm} \mathrm{~L})$ as a restrictor. The restrictor produces $c a$. 10-MPa, which significantly stabilizes the flow, and thus reduces the base line noise (ca. 1/3). An X-LC 3070UV detector with a 2.6- $\mu \mathrm{L}$ volume flow cell and 5-mm path length was used to measure the peak broadening of the UHPLC system and the reaction system. An X-LC 3120FP FL detector was used to detect derivatized amines with OPA. A JASCO ChromNAV chromatography data system was used for data processing. All components were from JASCO Corp. (Tokyo, Japan).

\section{Chemicals and columns}

All chemicals used in this study were of analytical grade, and the solvents used were of HPLC grade. Amines and amino acids standards, except for spermidine and spermine, were purchased from Wako Pure Chemicals (Osaka, Japan). Spermidine and spermine were purchased from Tokyo Chemical Industry (Tokyo, Japan).

Ultra-pure water was obtained from Milli-Q water purification systems (Merck Millipore, Billerica, MA). Stock solutions of amines and amino acids standards were prepared as aqueous solutions of $0.1 \mathrm{M}$ hydrochloric acid containing $2.5 \mathrm{mmol}$ each. We used a $2.2 \mu \mathrm{m}$ YMC-Triart C18 material (prototype) packed in two different sizes: $2.0 \mathrm{~mm}$ i.d. $\times 50 \mathrm{~mm} \mathrm{~L}$ and $3.0 \mathrm{~mm}$ i.d. $\times 50 \mathrm{~mm} \mathrm{~L}$ (YMC, Kyoto, Japan). Solid-phase extraction (SPE) cartridges used in this study were InertSep MC-2 purchased from GL Sciences (Tokyo, Japan). The solid phase was a methacrylate polymer resin with a weak cation exchanger.

\section{Food samples}

Two kinds of wine were purchased at a liquor shop. Red wine and noble rot wine were from Argentina and France, respectively. Wines were diluted with ultra-pure water by 50 times, and filtrated with a $0.2 \mu \mathrm{m}$ membrane filter; then, $2 \mu \mathrm{L}$ of the sample was injected to the UHPLC system.

Vietnamese fish sauce was purchased at a grocery store. It was made from fermented fish, and widely used in South East Asian countries as a seasoning. We chose the fish sauce as a sample because it is artificially spoiled under control. The fish sauce was pretreated by an SPE cartridge for removing an abundance of monoamines and amino acids. ${ }^{19,20}$ Before loading onto the SPE cartridge, it was diluted with ultra-pure water 5 times, and with $10 \mathrm{mM}$ phosphate buffer 2 times. Then, the sample was pretreated by the procedure given in Fig. S1 in Supporting Information.

\section{Method for estimating the contribution of the peak broadening of} each section

In the case of post-column derivatization with FL detection in the UHPLC, the total peak broadening includes three different sources of peak broadenings, caused by: 1) the UHPLC system itself, 2) the reaction coil, and 3) the detector flow cell. It is expressed by the following equation:

$$
V_{\mathrm{p} \mathrm{Obs}}{ }^{2}=V_{\mathrm{p} \mathrm{UHPLC}}{ }^{2}+V_{\text {p Deriv }^{2}}+V_{\mathrm{p} \text { cell }^{2}},
$$

where $V_{\mathrm{p} \text { Obs }}{ }^{2}=$ total peak volume observed, $V_{\mathrm{p} \text { UHPLC }^{2}}=$ peak volume generated by the UHPLC system, $V_{\mathrm{p} \text { Deriv }}{ }^{2}=$ peak volume added by the reaction coil, and $V_{\mathrm{p} \text { cell }}{ }^{2}=$ peak volume added by the detector's flow cell.

In order to estimate the contribution of the post-column reaction system to the increase in the total peak volume, we set up the systems one with and the other without the reaction system. Histamine, which is one of the analytes considered in this study, could be easily detected by a UV detector without derivatization. Therefore, we used the compound to measure the peak widths with and without the derivatization system.

First, we measured the total peak volumes of histamine peaks that were eluted at different retention factors $(k=3,5$, and 7) without the reaction system by UV detection. This range of retention factors was estimated in consideration of the peak volumes with gradient elution. The columns that we used were of $2.0 \mathrm{~mm}$ i.d. and $3.0 \mathrm{~mm}$ i.d., packed with a $2.2 \mu \mathrm{m}$ particle C18 material (Prototype YMC-Triart C18). The observed peak volume (1) $V_{\mathrm{p} \text { Obsi }}{ }^{2}$ is expressed by Eq. 1 without the $V_{\mathrm{p} \text { Deriv }}{ }^{2}$ term on the right-hand side of the equation. Then, we measured the total peak volumes of the histamine peaks that were eluted at different retention factors $(k=3,5$, and 7) with the reaction system with reaction coils of different lengths and diameters. The observed peak volume (2) $V_{\mathrm{p} \text { Obs } 2}{ }^{2}$ is expressed by Eq. 1 . Now, we can evaluate the peak broadening caused only by the reaction system $V_{\mathrm{p} \text { Deriv }}{ }^{2}$ by subtracting $V_{\mathrm{p} \text { Obs1 }}{ }^{2}$ from $V_{\mathrm{p} \text { Obs } 2^{2}}$, as shown below: 
(A) $2.0 \mathrm{~mm}$ I.D. column

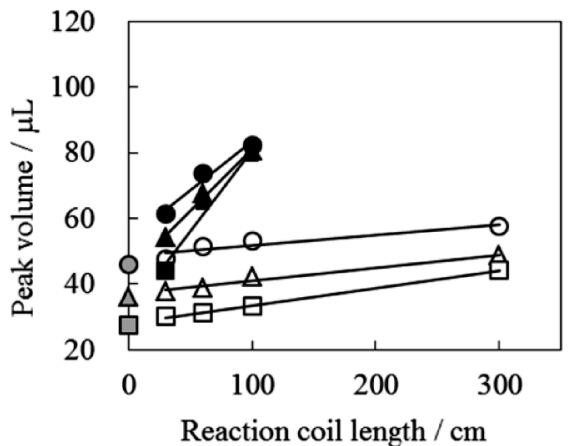

(B) $3.0 \mathrm{~mm}$ I.D. column

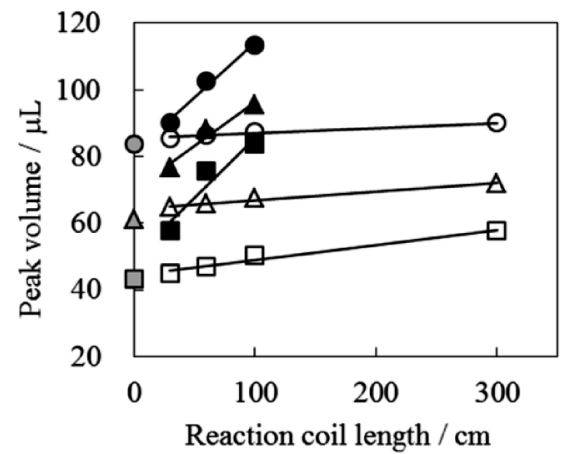

$\circ k=7$, without reaction coil $\bullet k=7,0.25 \mathrm{~mm}$ I.D. reaction coil $\bigcirc k=7,0.13 \mathrm{~mm}$ I.D. reaction coil

$\Delta k=5$, without reaction coil $\Delta k=5,0.25 \mathrm{~mm}$ I.D. reaction coil $\Delta k=5,0.13 \mathrm{~mm}$ I.D. reaction coil

$\square k=3$, without reaction coil $\square k=3,0.25 \mathrm{~mm}$ I.D. reaction coil $\square k=3,0.13 \mathrm{~mm}$ I.D. reaction coil

(C)

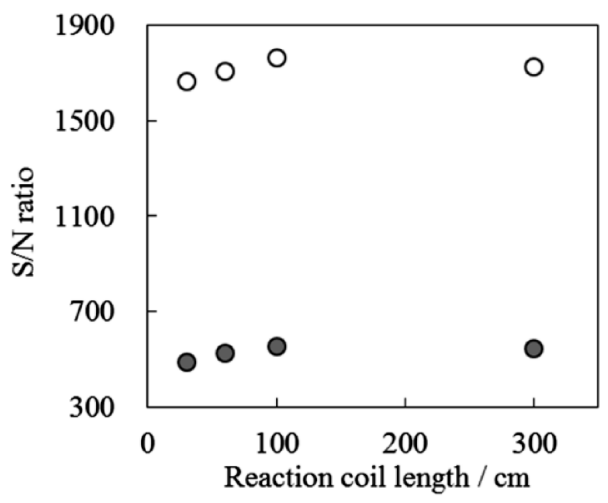

$01 \mu \mathrm{L}$ cell
(D)

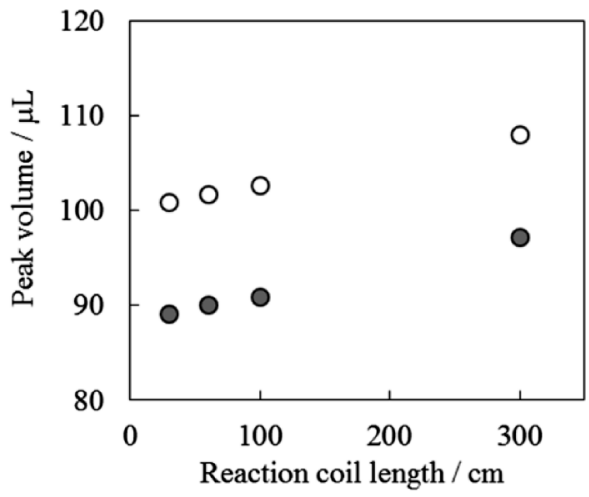

O $5 \mu \mathrm{L}$ cell

Fig. 2 Observed peak volume of histamine with UV detection, $2.0 \mathrm{~mm}$ i.d. column (A) and $3.0 \mathrm{~mm}$ i.d. column (B). Effect of a $0.13 \mathrm{~mm}$ i.d. reaction coil length and an FL detector cell volume on the $S / N$ ratio of histamine peak (C) and the total peak volumes of histamine (D).

$$
V_{\mathrm{p} \text { Deriv }}^{2}=V_{\mathrm{p} \mathrm{Obs} 2^{2}}-V_{\mathrm{p} \mathrm{Obs} 1^{2}}
$$

From these results, we estimated the contribution of the peak broadening of each section, and chose the optimal internal diameters of the column and the reaction coil. Finally, we investigated the optimal length of the reaction coil with the fluorescence detector.

Chromatographic conditions for estimating the contribution of peak broadening

The analysis conditions in these experiments were as follows. Eluent A was an aqueous solution of $10 \mathrm{mM}$ sodium dihydrogen phosphate and $150 \mathrm{mM}$ sodium perchlorate (adjusted to $\mathrm{pH} 2.0$ with phosphoric acid) containing $20 \mathrm{mM}$ 1-pentanesufonic acid sodium salt. Eluent B was a mixture of $10 \mathrm{mM}$ sodium dihydrogen phosphate and $150 \mathrm{mM}$ sodium perchlorate (adjusted to $\mathrm{pH} 2.0$ with phosphoric acid)-methanol (50/50) containing $20 \mathrm{mM}$ 1-pentanesulfonic acid sodium salt. The derivatization reagent was a mixture of $0.2 \mathrm{M}$ boric acid buffer-0.08\% (w/v) OPA dissolved in methanol-Brij35 (30\%)-3-mercaptopropionic acid (100/4/0.2/0.2). The eluent flow rates were $0.3 \mathrm{~mL} / \mathrm{min}$ (with $2.0 \mathrm{~mm}$ i.d. column) and $0.6 \mathrm{~mL} / \mathrm{min}$ (with $3.0 \mathrm{~mm}$ i.d. column), respectively. The derivatization reagent flow rates were $0.15 \mathrm{~mL} / \mathrm{min}$ (with
$2.0 \mathrm{~mm}$ i.d. column) and $0.3 \mathrm{~mL} / \mathrm{min}$ (with $3.0 \mathrm{~mm}$ i.d. column), respectively. The elution was performed in the isocratic mode with a mixture of eluents $\mathrm{A}$ and $\mathrm{B}$ in different eluent $\mathrm{B}$ concentrations: $15 \%$ for $k=3,8 \%$ for $k=5$, and $4 \%$ for $k=7$, respectively. The column temperature was maintained at $40^{\circ} \mathrm{C}$. The reaction system was kept at room temperature. UV detections were carried out at $210 \mathrm{~nm}$ (without the reaction system) and $345 \mathrm{~nm}$ (with the reaction system), and FL detection was carried out at $345 \mathrm{~nm}$ for excitation and $455 \mathrm{~nm}$ for emission. The injection volume was $1 \mu \mathrm{L}$. The concentrations of histamine were $100 \mathrm{nmol} / \mathrm{mL}$ for UV detection and $50 \mathrm{nmol} / \mathrm{mL}$ for FL detection, respectively.

Optimization of the chromatographic conditions for the separation of amines and amino acids

Because foods rich in polyamines contain an abundance of amino acids, it is necessary to separate amines from basic amino acids. We examined the effects of the concentrations of the ion-pair reagent and sodium perchlorate in the eluent and the eluent $\mathrm{pH}$ on the separation of amines and amino acids.

The concentrations of sodium perchlorate and 1-pentanesufonic acid sodium salt, and the $\mathrm{pH}$ of the eluents were examined in the ranges of $125-175 \mathrm{mM}, 10-30 \mathrm{mM}$ and $\mathrm{pH} 1.9-2.3$, respectively. The percentage of methanol in eluent $\mathrm{B}$ was 
changed to 80 . The eluent and the reagent flow rates were 0.65 and $0.33 \mathrm{~mL} / \mathrm{min}$, respectively. The gradient profile of eluent $\mathrm{B}$ was $3 \%(0-0.60 \mathrm{~min}), 3-20 \%(0.60-3.65 \mathrm{~min}), 20-55 \%$ $(3.65-4.70 \mathrm{~min}), \quad 55-70 \% \quad(4.70-6.40 \mathrm{~min}), \quad 70-100 \%$ $(6.40-6.45 \mathrm{~min}), \quad 100-100 \% \quad(6.45-8.00 \mathrm{~min}), \quad 100-3 \%$ (8.00 - $8.05 \mathrm{~min})$, and $3-3 \%$ (8.05 - $10.5 \mathrm{~min})$. The column was prototype YMC-Triart $\mathrm{C} 18(2.2 \mu \mathrm{m}, 3.0 \mathrm{~mm}$ i.d. $\times$ $50 \mathrm{~mm} \mathrm{~L}$ ). The temperature of the column and the reaction were maintained at $40^{\circ} \mathrm{C}$. FL detection was carried out at $345 \mathrm{~nm}$ for excitation and $455 \mathrm{~nm}$ for emission. The injection volume was $2 \mu \mathrm{L}$. The concentrations of the standard mixture were as follows: $7.5 \mathrm{pmol} / \mu \mathrm{L}$ for tryptamine, $12.5 \mathrm{pmol} / \mu \mathrm{L}$ for histamine, spermidine, agamatine, tyramine, and spermine, $25 \mathrm{pmol} / \mu \mathrm{L}$ for putrescine, cadaverine, and 8 amino acids.

\section{Results and Discussion}

Contribution of the internal diameter of the reaction coil and column to peak broadening

Figure 2 shows the relationship between the peak volumes of the histamine peaks $(k=3,5$, and 7) separated on the $2.0 \mathrm{~mm}$ i.d. (A) and $3.0 \mathrm{~mm}$ i.d. (B) columns versus the length of the reaction coil (reaction coil i.d. $=0.25$ and $0.13 \mathrm{~mm}$ ). Plots at 0 $\mathrm{cm}$ of the reaction coil length indicate the peak volumes of histamine peaks without the reaction system. The observed peak volumes without the reaction system on a $2.0 \mathrm{~mm}$ i.d. column were $27.5 \mu \mathrm{L}(k=3), 36.0 \mu \mathrm{L}(k=5)$, and $45.9 \mu \mathrm{L}$ $(k=7)$, respectively. Those on a $3.0 \mathrm{~mm}$ i.d. column were $43.2 \mu \mathrm{L} \quad(k=3), \quad 61.2 \mu \mathrm{L} \quad(k=5), \quad$ and $83.7 \mu \mathrm{L} \quad(k=7)$, respectively. As shown in this figure, the peak volumes on both the $2.0 \mathrm{~mm}$ and $3.0 \mathrm{~mm}$ i.d. columns became greater with increasing the reaction coil length; also, the peak volumes with a $0.25 \mathrm{~mm}$ i.d. reaction coil were unacceptably larger than those with a $0.13 \mathrm{~mm}$ i.d. reaction coil.

If we allow a $10 \%$ increase in the peak volume, a combination of the $3.0 \mathrm{~mm}$ i.d. column and the $0.13 \mathrm{~mm}$ i.d. reaction coil would be the best choice in order to maintain a decent column performance, including the post-column derivatization detection system.

\section{Reaction coil length and detector flow cell volume}

After having decided on the optimal internal diameters of the column and the reaction coil, we investigated the optimal length of the reaction coil with the fluorescence detector. Figure $2 \mathrm{C}$ shows the effect of the reaction coil length on the fluorescence detector's signal-to-noise $(S / N)$ ratio for the histamine peak. As shown in the figure, the $S / N$ ratio becomes higher as the reaction coil length becomes longer; however, the trend ends at a length of $100 \mathrm{~cm}$. This means that the length corresponds to a reaction time of $0.9 \mathrm{~s}$, which is long enough to yield the maximum sensitivity. The $S / N$ ratio with the $5 \mu \mathrm{L}$ flow cell is 3-times higher than those with the $1 \mu \mathrm{L}$ flow cell; therefore, we decided to use the $5 \mu \mathrm{L}$ flow cell. As for the observed total peak broadening in terms of the peak volume, it is $103 \mu \mathrm{L}$, as shown in Fig. 2D. Considering the above results, we decided to use the $100 \mathrm{~cm}$ long reaction coil and the $5 \mu \mathrm{L}$ fluorescence detector flow cell. The optimization we demonstrated above is applicable to simultaneous analyses of amines with gradient elution.

We used a U-shaped coil that had $c a .15 \mathrm{~cm}$ radius for investigating the reaction system. However, we used a tightly wound coiled tube $12 \mathrm{~mm}$ in diameter for the actual analysis of amines. This may have further reduced the extra-column peak broadening due to the secondary flow within the reaction tube caused by a small radius of the coiled tube.
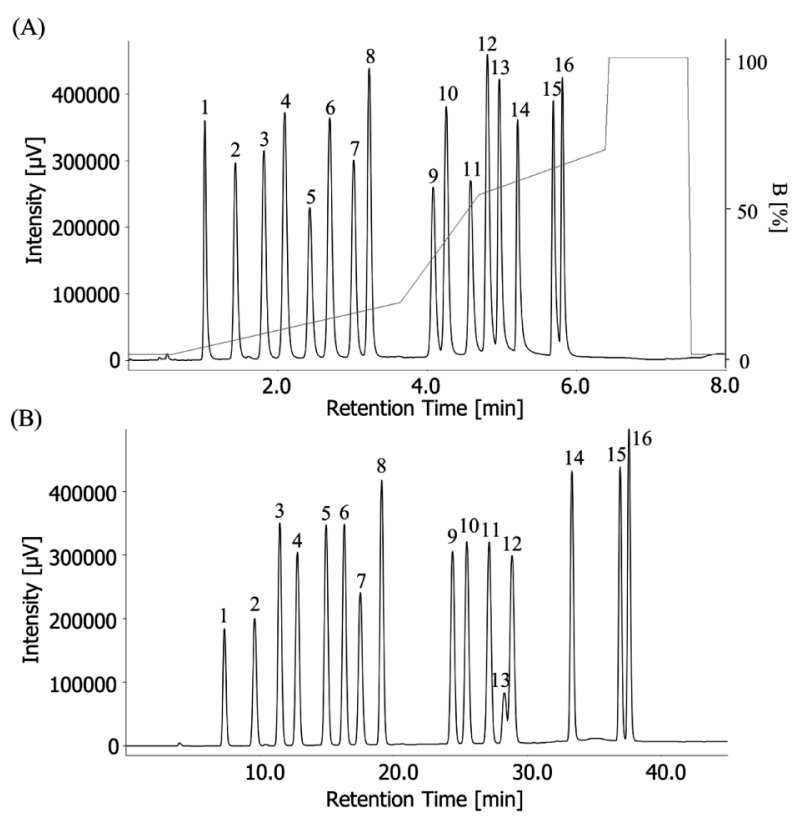

Fig. 3 Chromatogram of a standard mixture of 8 amines and 8 amino acids by using UHPLC (A). Tryptamine: 3 pmol $/ \mu \mathrm{L}$, histamine, spermidine, agamatine, tyramine, and spermine: $5 \mathrm{pmol} / \mu \mathrm{L}$, putrescine, cadaverine, and 8 amino acids: $10 \mathrm{pmol} / \mu \mathrm{L}$. The peak identification numbers are listed in Table 1. See the text for the elution conditions. A chromatogram by the conventional HPLC is also shown for a comparison (B). All amines and amino acids, $25 \mathrm{pmol} / \mu \mathrm{L}$; eluent flow rate, $0.65 \mathrm{~mL} / \mathrm{min}$; reagent flow rate, $0.3 \mathrm{~mL} / \mathrm{min}$. Gradient conditions: $\mathrm{B} \%=3 \%(0-4.00 \mathrm{~min}), 3-20 \%(4.00-25.00 \mathrm{~min})$, $20-55 \% \quad(25.00-32.00 \mathrm{~min}), \quad 55-60 \% \quad(32.00-45.00 \mathrm{~min})$, $60-100 \% \quad(45.00-45.05 \mathrm{~min}), \quad 100-100 \% \quad(45.05-52.00 \mathrm{~min})$, $100-3 \%$ (52.00-52.05 min), 3-3\% (52.05- $75.00 \mathrm{~min})$. Column, YMC-Triart C18 $(5 \mu \mathrm{m}, 4.6 \mathrm{~mm}$ i.d. $\times 150 \mathrm{~mm} \mathrm{~L})$; reaction coil, $0.25 \mathrm{~mm}$ i.d. $\times 700 \mathrm{~cm} \mathrm{~L}$; injection volume, $10 \mu \mathrm{L}$. Other conditions were the same as those of UHPLC.

\section{Effect of the ion-pair reagent concentration in the eluent on the retention}

We studied the optimal concentration of 1-pentanesulfonic acid sodium for improving the retention of basic samples. The best separation was observed with $20 \mathrm{mM}$. Details about the optimization are given in Fig. S2(A) in Supporting Information.

Effect of the sodium perchlorate concentration in the eluent on the retention and peak shape

We investigated the optimal concentration of sodium perchlorate for improving the peak shapes and selectivity. Consequently, the retention became shorter with increasing the concentration. However, the salting-out effect was not seen, the selectivity of the separation was changed and peak shapes were improved. The best separation was observed with $150 \mathrm{mM}$. Details about the optimization are given in Fig. S2(B) in Supporting Information.

\section{Effect of the eluent $\mathrm{pH}$ on the retention and the peak shape}

We studied the optimal $\mathrm{pH}$ of the eluent for suppressing any peak tailing of basic samples on a $\mathrm{C} 18$ column caused by the effect of residual silanol groups. The best separation was observed at $\mathrm{pH}$ 2.0. Since spermine has more amino groups, the peak tailing of the peak could not completely be suppressed, even with $\mathrm{pH}$ values lower than 2.0. The retention of amines was hardly affected by the $\mathrm{pH}$ of the eluent; however, the change 
Table 1 Relative standard deviations (RSD\%) for the retention times and peak areas, detection limits, and recoveries of amines

\begin{tabular}{|c|c|c|c|c|}
\hline \multirow{2}{*}{$\begin{array}{l}\text { Amine and } \\
\text { amino acid }\end{array}$} & \multicolumn{2}{|c|}{$\mathrm{RSD} \%^{\mathrm{a}}$} & \multirow{2}{*}{$\begin{array}{c}\text { Detection } \\
\text { limit } / \\
\text { fmol }\end{array}$} & \multirow{2}{*}{$\begin{array}{c}\text { Recovery } \\
\text { rate, } \%\end{array}$} \\
\hline & $t_{\mathrm{R}}$ & $\begin{array}{l}\text { Peak } \\
\text { area }\end{array}$ & & \\
\hline 1. Putrescine & 0.60 & 1.27 & 73.3 & 99.7 \\
\hline 2. Cadaverine & 0.82 & 0.78 & 78.8 & 98.1 \\
\hline 3. Histamine & 0.36 & 1.54 & 40.1 & 99.8 \\
\hline 4. Arginine & 0.41 & 1.18 & 64.5 & - \\
\hline 5. Valine & 0.21 & 1.60 & 105.7 & - \\
\hline 6. Methionine & 0.20 & 1.40 & 68.7 & - \\
\hline 7. Spermidine & 0.21 & 1.12 & 40.7 & 98.1 \\
\hline 8. Agmatine & 0.19 & 1.26 & 28.3 & 99.4 \\
\hline 9. Tyrosine & 0.15 & 1.66 & 95.9 & - \\
\hline 10. Tyramine & 0.15 & 0.97 & 33.0 & 96.2 \\
\hline 11. Isoleucine & 0.15 & 1.29 & 94.8 & - \\
\hline 12. Leucine & 0.16 & 1.19 & 54.3 & - \\
\hline 13. Spermine & 0.18 & 1.13 & 29.0 & 98.7 \\
\hline 14. Phenylalanine & 0.15 & 1.41 & 69.9 & - \\
\hline 15. Tryptophan & 0.12 & 0.98 & 64.8 & - \\
\hline 16. Tryptamine & 0.11 & 1.04 & 18.0 & 98.2 \\
\hline
\end{tabular}

a. Reproducibilities of the retention times and peak areas $(n=10)$. b. $S / N=3$.

in the $\mathrm{pH}$ of the eluent remarkably influences the retention of basic amino acids. Details about the optimal $\mathrm{pH}$ investigation are given Fig. S2(C) in Supporting Information.

Figure $3 \mathrm{~A}$ shows a chromatogram of the standard mixture containing amines and amino acids separated under the optimized conditions by using UHPLC. The gradient profile of eluent B (\%) is also shown. The peak volumes of amines with the reaction system and gradient elution by fluorescence detection were $61-100 \mu \mathrm{L}$. That was equal to the previously described range of the peak volumes of the histamine peak $(k=3,5$, and 7) with the reaction system and isocratic elution by fluorescence detection. Figure 3B shows a chromatogram of the standard mixture of amines and amino acids by using conventional HPLC for a comparison. The analysis time and solvent consumption in UHPLC were reduced by a factor of 7 compared with those in conventional HPLC.

The intensity of the spermine peak on the conventional HPLC chromatogram is notably lower than that on the UHPLC chromatogram. It is known that basic compounds often strongly interact with residual silanol groups on the $\mathrm{C} 18$ stationary phase, and result in irreversible adsorption, resulting in the unrepeatable peak and the bad peak shape. The authors' other investigation on the elution condition, not shown here, using $3.0 \mathrm{~mm}$ i.d. columns with 50 and $100 \mathrm{~mm}$ in lengths, also showed that the $100-\mathrm{mm}$ column gave an unstable peak intensity for spermine. Sometimes the intensity was only $1 / 5$ of that with the $5 \mathrm{~cm}$ column. This result suggests that the longer is the column, the stronger does the silanol group's effect become.

\section{Linear dynamic range}

Linearities of amines and amino acids were tested at 5 concentration levels, ranging from 0.12 to $12 \mathrm{pmol} / \mu \mathrm{L}$ (tryptamine), from 0.2 to $20 \mathrm{pmol} / \mu \mathrm{L}$ (histamine, spermidine, agamatine, tyramine, and spermine), and from 0.4 to $40 \mathrm{pmol} / \mu \mathrm{L}$ (putrescine, cadaverine, and 8 amino acids), respectively. The correlation coefficients $(r)$ were calculated to be 0.9999 by using the results of the linear dynamic range analyses of all 8 amines and 8 amino acids.
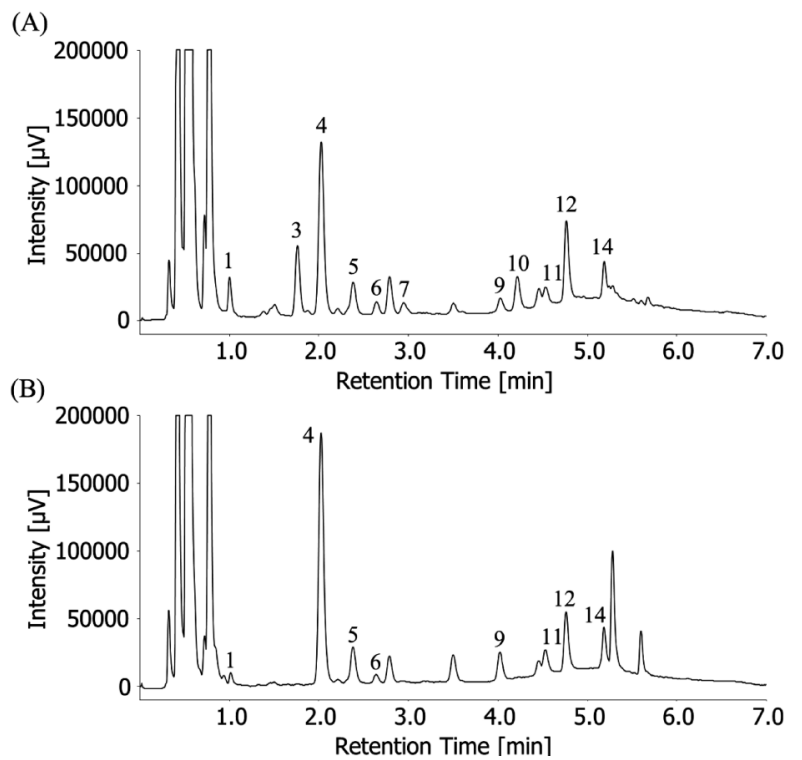

Fig. 4 Chromatograms of wine samples, red wine (A), noble rot wine (B). See Table 1 for peak identification.

Reproducibility of the retention time and the peak area

The reproducibilities of the retention times and the peak areas were calculated using the results of 10 consecutive analyses of the standard mixture of 8 amines and 8 amino acids (tryptamine, $1.5 \mathrm{pmol} / \mu \mathrm{L}$; histamine, spermidine, agamatine, tyramine, and spermine, $2.5 \mathrm{pmol} / \mu \mathrm{L}$; putrescine, cadaverine, and 8 amino acids, $5 \mathrm{pmol} / \mu \mathrm{L})$. These results are listed in Table 1. The relative standard deviations were $0.11-0.82 \% \mathrm{RSD}$ for the retention time, and $0.78-1.66 \%$ for the peak area, respectively.

\section{Detection limit}

The 4th column of Table 1 gives the detection limits $(S / N=3)$ for 8 amines and 8 amino acids, calculated from the chromatogram of the standard mixture (tryptamine, $0.3 \mathrm{pmol} / \mu \mathrm{L}$; histamine, spermidine, agamatine, tyramine, and spermine, $0.5 \mathrm{pmol} / \mu \mathrm{L}$; putrescine, cadaverine, and 8 amino acids, $1 \mathrm{pmol} / \mu \mathrm{L})$. Highly sensitive detection has been realized by fluorescence detection; the detection limits $(S / N=3)$ were 18.0 - 105.7 fmol.

\section{Applications to amine analysis in wines}

The occurrence of amines in wine is related to alcoholic fermentation by yeasts and malolactic fermentation by lactic bacteria. $^{21-24}$ Also, the contents of amines in wines are influenced by the producing environment and the vinification process, including the climate, soil, grape variety, microorganism strains, treat of grape, and storage method. 2,25-29

Figures 4A and 4B show chromatograms of wine samples. As shown in this figure, red wine (A) contains putrescine $(6.92 \mu \mathrm{g} /$ $\mathrm{mL})$, histamine $(9.00 \mu \mathrm{g} / \mathrm{mL})$, spermidine $(2.34 \mu \mathrm{g} / \mathrm{mL})$, and tyramine $(4.96 \mu \mathrm{g} / \mathrm{mL})$, but noble rot wine (B) contains only putrescine $(2.24 \mu \mathrm{g} / \mathrm{mL})$. Ibe reported the contents range of amines in 75 commercial wines. ${ }^{30}$ Our results are consistent with his report.

\section{Applications to amine analysis in fish sauce}

As described previously, fish sauce was subjected to an SPE pretreatment in order to remove an abundance of monoamines and amino acid. As shown in Fig. S1 in Supporting Information, 


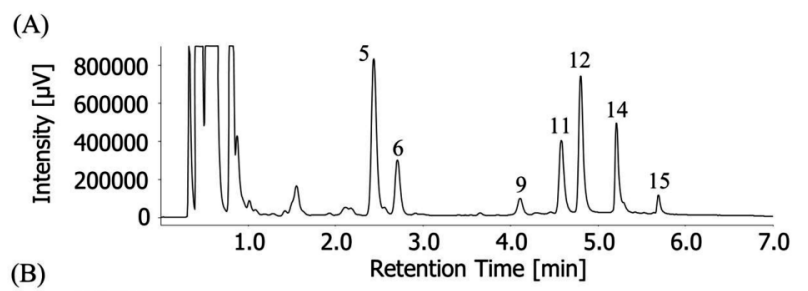

(B)

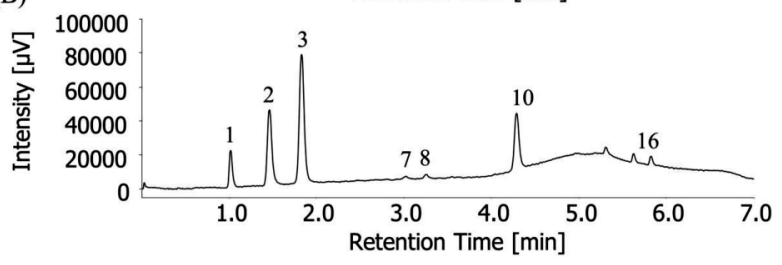

Fig. 5 Chromatograms of fish-sauce samples pretreated with SPE. (A) Removed impurities by SPE pretreatment, (B) eluted amines contained in the flash buffer from SPE. See Table 1 for peak identification.

we loaded the SPE cartridge with the standard mixture of amines and amino acids, which were diluted twice with $10 \mathrm{mM}$ phosphate buffer ( $\mathrm{pH}$ 6.8). The standard mixture contained tryptamine, $75 \mathrm{pmol} / \mu \mathrm{L}$; histamine, spermidine, agamatine, tyramine, and spermine, $125 \mathrm{pmol} / \mu \mathrm{L}$; putrescine, cadaverine, and 8 amino acids, $250 \mathrm{pmol} / \mu \mathrm{L}$.

First, we tried to elute amines with only a phosphateperchlorate solution. The recovery of tryptamine was less than $50 \%$. The recovery was improved by eluting with $2.5 \mathrm{~mL}$ of a 50/50 mixture of phosphate-perchlorate and methanol. However, the peak shape of cadaverine and histamine became worse due to the influence of the methanol content in the final sample solution. Therefore, the sample solution was diluted 4 times with eluent A, after being filled up with eluent A. We then injected the diluted sample solution. The peak shape of cadaverine and histamine were significantly improved. Chromatograms of the standards and different SPE cleanup are shown in Fig. S3 in the Supporting Information. The recoveries of amines are listed in the 5th column of Table 1. As can be seen, high recoveries of between 96.2 and $99.8 \%$ were observed. Therefore, we applied this solid-phase extraction method to the pretreatment of fish sauce.

Figures 5A and 5B show chromatograms of fish sauce; Fig. 5A is a chromatogram of removed impurities by SPE, and Fig. 5B is of cleaned amines by SPE. As shown in this chromatogram, the fish sauce (Fig. 5B) contained putrescine $(427 \mu \mathrm{g} / \mathrm{mL})$, cadaverine $(1270 \mu \mathrm{g} / \mathrm{mL})$, histamine $(88 \mu \mathrm{g} / \mathrm{mL})$, spermidine $(29.1 \mu \mathrm{g} / \mathrm{mL})$, agmatine $(30.1 \mu \mathrm{g} / \mathrm{mL})$, and tryptamine $(66.5 \mu \mathrm{g} / \mathrm{mL})$. Nakazato et al. reported the contents of amines in 55 commercial fish sauces from Asia. ${ }^{31}$ Most of our results were consistent with his report, except for the histamine content. However, there is another report on 45 fish sauces that shows higher histamine contents, such as $729 \mathrm{mg} / \mathrm{kg}$ for histamine. ${ }^{32}$ Also, it is suggested that the high histamine content found in this study was influenced by protein decomposition by microorganisms and autolysis with aging. ${ }^{31,33}$ A broad peak that appeared from 4 to 7 min was the baseline shift due to the change in the fluorescent background of the eluent by the gradient elution. Such a baseline shift appears on every chromatogram, but it is more significant in Fig. 5B due to the higher sensitivity scale.

\section{Conclusions}

We have demonstrated the utility of post-column derivatization with OPA for UHPLC. The reaction system and separation condition were optimized. The analysis time and the solvent consumption required by UHPLC were reduced by 7 times, as compared with conventional HPLC ( 1 cycle: 75 to $11 \mathrm{~min}, 71.3$ to $10.5 \mathrm{~mL})$. Highly sensitive detections were obtained (detection limits $(S / N=3)$ : 18.0 to $105.7 \mathrm{fmol})$. Excellent reproducibilities were obtained (RSD\%: 0.11 to $0.82 \%$ (retention time), 0.78 to $1.66 \%$ (peak area)). The method of solid-phase extraction for food samples containing an abundance of contaminating substances was optimized. The analysis of amines using post-column derivatization by UHPLC was successfully applied to food analysis.

\section{Acknowledgements}

We are grateful to YMC, Kyoto Japan for kindly supplying YMC-Triart C18 prototype columns.

\section{Supporting Information}

Details about the SPE pretreatment procedure, optimization of the elution conditions and chromatograms of amine and amino acid standards with/without SPE pretreatment are shown as Figs. S1 - S3, respectively. These materials are available free of charge on the Web at http://www.jsac.or.jp/analsci/.

\section{References}

1. I. S. Krull, Z. Deyl, and H. Lingeman, J. Chromatogr., B, 1994, 659, 1.

2. S. Hernández-Cassou and J. Saurina, J. Chromatogr., B, 2011, 879, 1270.

3. R. S. Deelder, M. G. F. Kroll, and J. H. M. Van den Berg, J. Chromatogr., A, 1976, 125, 307.

4. R. S. Deelder, M. G. F. Kroll, A. J. B. Beeren, and J. H. M. Van den Berg, J. Chromatogr., A, 1978, 149, 669.

5. R. S. Deelder, A. T. J. M. Kuijpers, and J. H. M. Van den Berg, J. Chromatogr., A, 1983, 255, 545.

6. M. Yoshioka, Z. Tamura, M. Senda, and T. Miyazaki, J. Chromatogr., B, 1985, 344, 345.

7. T. Takeuchi, S. Saito, and D. Ishii, J. Chromatogr., A, 1983, $258,125$.

8. M. Zhang, T. Caragine, H. Wang, P. S. Cohen, G. Botchkina, K. Soda, M. Bianchi, P. Ulroch, A. Cerami, B. Sherry, and K. J. Tracey, J. Exp. Med., 1997, 185, 1759.

9. K. Soda, Y. Kano, T. Nakamura, K. Kasono, M. Kawakami, and F. Konishi, J. Immunol., 2005, 175, 237.

10. H. M. H. van Eijk, D. R. Rooyakkers, and N. E. P. Deutz, J. Chromatogr., A, 1996, 730, 115.

11. M. Venza, M. Visalli, D. Cicciu, and D. Teti, J. Chromatogr., $B, \mathbf{2 0 0 1}, 757,111$.

12. K. B. Male and J. H. T. Luong, J. Chromatogr., A, 2001, 926, 309.

13. A. Zotou, Z. Loukou, E. Soufleros, and I. Stratis, Chromatographia, 2003, 57, 429.

14. Z. Loukou and A. Zotou, J. Chromatogr., A, 2003, 996, 103.

15. V. Lozanov, S. Petrov, and V. Mitev, J. Chromatogr., A, 
2004, 1025, 201.

16. M. C. Vidal-Carou, F. Lahoz-Portolés, S. Bover-Cid, and A. Mariné-Font, J. Chromatogr., A, 2003, 998, 235.

17. T. Lavizzari, M. T. Veciana-Nogués, S. Bover-Cid, A. Mariné-Font, and M. C. Vidal-Carou, J. Chromatogr., A, 2006, 1129, 67.

18. M. L. Latorre-Moratalla, J. Bosch-Fusté, T. Lavizzari, S. Bover-Cid, M. T. Veciana-Nogués, and M. C. Vidal-Carou, J. Chromatogr., A, 2009, 1216, 7715.

19. S. Moret and L. S. Conte, J. Chromatogr., A, 1996, 729, 363.

20. T. Sakamoto, K. Akaki, and H. Hiwaki, Food Hyg. Saf. Sci., (in Japanese with English summary) 2010, 51, 115.

21. C. Buteau, C. L. Duitschaever, and G. C. Ashton, Am. J. Enol. Vitic., 1984, 35, 228.

22. C. S. Ough and C. E. Daudt, Am. J. Enol. Vitic., 1981, 32, 185.

23. P. M. Izquierdo Cañas, E. Garcia Romero, S. Gómez Alonso, M. Fernández González, and M. L. L. Palop Herreros, J. Food Comp. Anal., 2008, 21, 731.

24. M. C. Vidal-Carou, A. Ambatlle-Espunyes, M. C. Ulla-
Ulla, and A. Mariné-Font, Am. J. Enol. Vitic., 1990, 41, 160.

25. C. Ancín-Azpilicueta, A. González-Marco, and N. JiménezMoreno, Crit. Rev. Food Sci. Nutr., 2008, 48, 257.

26. A. P. Marques, M. C. Leitáo, and M. V. San Romão, Food Chem., 2008, 107, 853.

27. F. Cecchini and M. Morassut, Food Chem., 2010, 123, 263.

28. L. Manfroi, P. H. A. Silva, L. A. Rizzon, P. S. Sabaini, and M. B. A. Glória, Food Chem., 2009, 116, 208.

29. I. Rosi, F. Nannelli, and G. Giovani, LWT-Food Sci. Technol., 2009, 42, 525.

30. A. Ibe, Ann. Rep. Tokyo Metr. Inst. P.H. (in Japanese), 2004, 55,13 .

31. M. Nakazato, C. Kobayashi, Y. Yamajima, Y. Tateishi, Y. Kawai, and K. Yasuda, Ann. Rep. Tokyo Metr. Res. Lab. P.H. (in Japanese), 2002, 53, 95.

32. R. Stute, K. Petridis, H. Steinhart, and G. Biernoth, Eur Food Res. Technol., 2002, 215, 101.

33. N. G. Sanceda, E. Suzuki, M. Ohashi, and T. Kurata, J. Agric. Food Chem., 1999, 47, 3596. 